\title{
Mine closure - do we miss the opportunities?
}

\author{
AG Bjelkevik Tailings Consultants Scandinavia AB (TCS), Sweden
}

TE Bohlin Tailings Consultants Scandinavia AB (TCS), Sweden

\begin{abstract}
Mining operations have a big environmental impact wherever they are located. Unsuccessful operation and/ or inadequate planning for closure has in several cases increased the impact, causing costly environmental liabilities without finance. The consequence is, generalized, difficulties to get permits, in some countries more or less impossible. Metals and minerals are, however, necessary for our society and even more so with the "green transformation", i.e. the change from fossil fuels to sustainable sources of energy (windmills, solar power, electrical cars etc. etc.).
\end{abstract}

Mining has developed over centuries. With time, extraction processes have been refined resulting in a (still) increasing amount of waste materials, such as waste rock and tailings. The mining industry is the industry, globally, moving the largest volumes of materials. These materials are generalized a problem, a waste.

Traditionally, mining operations are run by engineers using logic, "straight lines", effective processes in order to produce good quality products. The waste materials produced have been, and still are, seen as a waste product, i.e. a problem to be solved as efficiently as possible at the lowest cost. Sometimes at a too low cost, which in the worst case may result in incidents or failures of tailings management facilities or inappropriate closure, none of them acceptable.

This paper will discuss, from the authors point of view, possible ways of how mining operations may change into a positive element within our society. This require a new mindset and a different strategy within the industry. The authors believe this change could be to "use" mining, i.e. the materials produced, to create a value. By this many things can probably be achieved like; improved reputation, society/ community engagement, long term commitment and safer long-term solutions. The authors believe that these are key ingredients to obtain acceptance for the industry and more constructive permitting processes.

Keywords: mine closure, creating value through mine closure, permit process, license to operate

\section{Introduction}

Today's society is dependent on metals. Now maybe more than ever before, as we're going into a "green transformation", the change from fossil fuels to sustainable sources of energy (e.g. wind and solar power, electric cars). The necessity of metals, and therefore mines, are viewed as a basic condition in this paper and will not be discussed further.

Over time high grade mines are becoming fewer resulting in more waste produced per produced metal. At the same time extraction processes have been more refined, which in most cases results in finer residues (i.e. finer tailings). This results in an increase of, and finer, residues, which creates an even bigger challenge when it comes to tailings management. Finer particle size normally reduces stability as the strength of the material and the ability to drain decreases. This can result in an impact during operations and at closure. Safe and long-term stable tailings management facilities (TMF) pose probably one of the highest risks related to mining operations as failure often result in disastrous consequences.

Mine footprints range from a few to the order of magnitude of hundred square kilometres, with potential impact on landscape and environment as well as society and community. Historically, and even today, the negative impacts have at some sites passed the level of acceptance. Most of the "unsuccessful stories" are often related to the management of the residues produced by mining ( tailings and waste rock). Inappropriate closure measures, failures and incidents have imposed unacceptable effects and costs for the societies, 
communities and states. The situation, i.e. the bad publicity, has affected the industry as a whole. The experience of the authors is that the situation has impacted relations with authorities and stakeholders, as well as the time and magnitude of the permitting processes.

This paper will, from the authors point of view, present the current requirements for closure and ideas and ways of how mining operations possibly could change into a positive element within society. The paper is based on the personal opinions of the authors, which experience within the mining industry comes mainly from work as consultants in Sweden as well as ICOLD and international conferences with focus on tailings management.

\section{$2 \quad$ Closure in Mining}

Closure in this paper refers to the period or phase after mining has stopped and remediation measures have been taken. The time for closure is here assumed to be 1,000 years or more.

This section will give a brief overview of requirements and guidelines for closure of mine residues within Sweden and internationally.

\subsection{Mine closure in Sweden}

The current Swedish guidelines for tailings dam safety, Guidelines for Tailings Dam Safety (GruvRIDAS, 2021 and $2012^{1}$ ) is a version of the Dam Safety Guideline for water dams (RIDAS, 2019) restructured by Swedish the mining industry in order to cover topics specific for tailings dams. In the restructuring, international guidelines have been considered including ICOLD ${ }^{2}, \mathrm{CDA}^{3}$, ANCOLD ${ }^{4}$ In GruvRIDAS (2021) it is stated that closure and remediation of TMFs aims for a transition of the facility into use for a different purpose, and that closure must aim for long term stability with respect to physical, chemical, ecological and social stability in order to achieve a sustainable final use.

The main documents covering mine closure in Sweden are;

- the Environmental Code (Sveriges Riksdag, 1998) and

- the Swedish Regulation on the Extraction of Waste (Sveriges Riksdag, 2013).

The environmental code specifies in general terms that the environmental permit should include conditions on measurements for decommissioning and remediation.

The Swedish Regulation on the Extraction of Waste (Sveriges Riksdag, 2013) states the owner of a mine has the responsibility to remediate the affected area to a satisfactory condition by executing, or finance the execution, of any necessary rehabilitation measures. There is also a requirement on a 'waste management plan' including for example;

1. A description on decommissioning plans for the mine site including:

a) A description on the intended land use after decommissioning.

b) Information on the physical stability of the facility, maximum emission of pollutants, environmental quality standards and objectives and other factors relevant for deciding on measurements to secure the affected area can be remediated to 'satisfactory conditions' and

\footnotetext{
${ }^{1}$ GruvRIDAS is under ongoing revision. 2021 the main document is revised followed by a planned revision of the more technical, detailed instructions to each chapter from 2021 and onwards.

${ }^{2}$ ICOLD, International Commission on Large dams, where Committee $L$ - Tailings Dams and Waste Lagoons focus on TMFs. https://www.icold-cigb.org/

${ }^{3}$ CDA, Canadian Dam Association. https://www.cda.ca/

${ }^{4}$ ANCOLD, Australian national committee to ICOLD. https://www.ancold.org.au/
} 
be further used without causing 'harm or inconvenience' for people or the environment and without compromising the possibility to follow the environmental quality standards.

c) Information on required measurements to ensure stability, remedial measurements, surveillance, restoring biodiversity and other required measurements during and after closure to follow environmental quality standards and meet objectives according to $b$ ).

d) Information on time perspective for the effect of the facility on human health and the environment and for remediation measurements.

2. That the facility after closure requires a minimum of surveillance and maintenance.

3. Responsibility on the owner to restore the affected area, specifically regarding protection of ground and water quality, flora and fauna, natural habitat, landscape, future land use and other health and environmental aspects.

4. A facility is to be considered closed first after inspection and approval of the regulatory authorities.

5. Responsibility on the owner to perform surveillance and maintenance (for example spillways, monitoring equipment, general surveillance and maintenance) during a time period set by the regulatory authorities. The regulatory authorities may take over this responsibility from the owner.

The effectiveness of the current Swedish praxis for financial security for closure was investigated (RIR, 2015) with recommendations to review the Swedish strategy for mine waste management. As a result, 'Proposed strategy for an environmentally sustainable management of mining waste' was published in 2017 (NV \& SGU, 2017:1) where the possibilities to avoid, or reuse, waste is emphasized as well as minimizing the potential negative environmental effects. The aim is suggested to be long-term, environmentally sustainable management in combination with national economical effective use of resources.

None of the documents or guidelines mention the possibility of creating value.

\subsection{Mine closure internationally}

Looking outside of Sweden some of (but not limited to) the most relevant international documents, or guidelines, on tailings mine closure are:

- ANCOLD: Guidelines on Tailings Dams (ANCOLD, 2012)

- ICOLD: Bulletin 153 Sustainable Design and Post-Closure Performance of Tailings Dams (ICOLD, 2013)

- CDA: Dam Safety Guidelines 2007 (2013 Edition) (CDA, 2013)

- Australian Government: Tailings Management (Australian Government, 2016)

- BREF: Best Available Techniques (BAT) Reference Document for the Management of Waste from Extractive Industries (EU, 2018)

- ICMM: Integrated Mine Closure: Good Practice guide (ICMM, 2019)

- GISTM: Global Industry Standard on Tailings Management (GISTM, 2020)

- GTR: Global Tailings Review: Towards Zero Harm - Chapter VIII Closure and Reclamation (GTR, 2020)

These documents and guidelines in general commonly state the following:

- Dam owners are accountable for the safe management of their dams throughout the dam's life cycle, from planning and design to decommissioning and closure.

- Tailings closure design starts during the initial stages of mine development, when decisions are made about site selection and tailings management. 
- Early and clear definition of the vision \& objectives for closure including potential land-use.

- One of the main objectives of closure is to achieve long-term physical, chemical, ecological and social stability, and a sustainable, environmentally appropriate after-use. Often referred to as compatible with the surrounding unmined landform or mimicking analogous, usually concave, natural profiles and revegetated to minimise erosion.

- Fundamental for mine closure is the need to consider closure as an integral part of the mine operations' core business and part of the life of mine planning (LOMP).

- There should be ongoing engagement of regulators and communities to get their perspectives and advice on the closure of the site as they may become the owner of the closed facility.

- Keep records of the design, construction, operation, and performance of the dam and the management of its safety.

- Risk \& opportunities, including 'what-if' scenarios for unplanned events (ex. temporary closure).

- Progressive closure and reclamation during operations should be implemented if possible.

- Remediation costs, post-closure monitoring and maintenance cost as well as costs of mitigating post-closure liabilities need to be considered and determined.

- Mining companies are, in most jurisdictions, required to financial assurances to cover the costs of reclamation and long-term care.

- The closure plan should be subjected to ongoing refinement, confirmation and update as the operations proceed from early planning phase through design, construction, operation and finally remediation for closure.

- Mine closure is a dynamic and iterative process that takes into account environmental, social and economic considerations.

- A closed facility must be monitored against success criteria defined at the design phase.

- The possibility and implications of premature closure must be considered throughout the operational phase.

Although the above statements are good and necessary, they do not really go beyond doing more, or different, than the 'minimum required'. In the following, the authors like to point at some quotations from the documents/ guidelines above, highlighting, or indicating steps towards a successful closure or even creating a value after closure, or in some ways goes beyond the general statements addressed above.

\subsubsection{ANCOLD (quotation)}

The storage must be designed with mine closure in mind, so as to create a permanent, maintenance free deposit that does not pose any unacceptable long-term environmental impact or risk.

\subsubsection{CDA (quotations)}

The dam safety review is required for complete life cycle management, from construction through major rehabilitation or replacement to closure or decommissioning of the dam.

Dam design, construction, operation, maintenance, decommissioning, closure, and all associated activities engage a broad spectrum of human and engineering disciplines.

\subsubsection{Australian Government (quotations)}

Stakeholder consultation, information sharing and dialogue should occur throughout the tailings storage facility (TSF) design, operation and closure phases, so viewpoints, concerns and expectations can be 
considered for all aspects of planning and execution. Regular, meaningful engagement between the company and affected communities is particularly important for developing trust and preventing conflict.

Decommissioned residue areas should have the capability to be used for productive community benefit, be safe and self-sustaining structures in the long term and allow future access to the residue for alternative uses.

In some cases, it will be possible to enhance the value of mined land to create a modified landscape that offers recreational, commercial or natural value that can be enjoyed in the future.

\subsubsection{BREF (quotation)}

Successive land use is defined as the aim to turn the area into something that is useful to the local community.

\subsubsection{ICMM (quotation)}

To successively validate criteria and build trust with communities and the regulators is important, especially for social transition in order to help reduce the negative impacts of social change for the workforce and communities connected to the mine site and to improve the legacy of benefits from mining activities.

\subsubsection{GISTM (quotation)}

PRINCIPLE 1: respect the rights of project-affected people and meaningfully engage them at all phases of the tailings facility lifecycle, including closure.

\subsubsection{GTR (quotations)}

Landform design, done well - and underpinned by good governance and collaboration between the mine, the regulator, and local communities - will result in a positive mining legacy for generations to come.

Current practice at most mining operations largely separates the long-term closure and reclamation of tailings facilities from the operational dam construction, tailings deposition, and geotechnical dam safety considerations. This artificial division leads to higher life-cycle costs, reduced performance and increased risk.

Landform design provides a framework for inclusion of all aspects of the life cycle of a tailings facility. This is a multidisciplinary process for building mining landforms, landscapes, and regions to meet agreed-upon land use goals and objectives. The process ideally begins with the initial designs of tailings landforms (or in the case of most existing sites, are adopted midstream) and continues long after operations have ceased.

Tailings landforms are important features in the mine's closure landscape that will last for millennia and will serve as a major component of a mine's enduring legacy. Mines, by working with their regulators and local communities, can help establish a positive mining legacy by returning lands for use by local communities in a timely manner.

Meaningful community engagement is undertaken as an ongoing process throughout the mine lifecycle, with the aim of ensuring that the concerns of local communities are heard and addressed. True collaboration, rather than just consultation, is key to closure reclamation success.

\subsubsection{Summary - Mine Closure internationally}

Most documents and guidelines state the same conditions for closure as listed under 2.2. However, some of them, quoted above, take closure and the responsibility further by emphasising;

- community and regulatory meaningful engagement and true collaboration (GISTM, 2020 and GTR, 2020),

- turning the area into something that is useful to the local community (EU, 2018),

- engage a broad spectrum of human and engineering disciplines in the closure process (CDA, 2013 and Australian Government, 2012) and that it is a multidisciplinary process (GTR, 2020), 
- enhance the value of mined land to create a modified landscape that offers recreational, commercial or natural value that can be enjoyed in the future (Australian Government, 2012) and

- positive mining legacy for generations to come (GTR, 2020).

\section{Discussion}

The society we have created on this earth needs metals, and the demand is increasing, and even more so due to the 'green transformation'. We therefore do need the mines. Mining operations are complex, changing over time and are usually very large. The size of the operations does result in an impact on the landscape and the environment, which is inevitable and something that needs to be accepted in order to meet the needs of society. It is also a fact that the ore bodies are located where they are. That we cannot change resulting in the location of a mine not being an option of choice. The basis of this paper is that we need mines and they need to be safe.

As ore grades reduce with time, the amount of mine residue (tailings and waste rock) increases. At the same time the tailings, in general, become finer as treatment processes generally improve the commodity exchange from finer grained material. This together results in a tailings more difficult to dewater and stabilize. All these factors increase the challenges to safe operation and closure. The basic requirements of a TMF are to provide safe, stable, non-polluting and economical storage of tailings, presenting negligible public health and safety risks, and acceptably low social and environmental impacts during its life cycle. To achieve this the physical stability is crucial, i.e. the number one challenge for the industry (according to the authors). If stability is not achieved, other requirements will inevitably not be met.

The historical failures, at a rate of of about 2 serious TMF failures per year (Wise Uranium, 2021), has resulted in unacceptable consequences and costs for the society. Due to this track record, the global mining industry has failed to prove our capability of operating and closing TMFs in a safe way. From this situation a seed of mistrust towards the industry has grown, peaking at the Brumadinho failure at the Feijão Iron Ore Mine in January 2019 (Robertson et.al., 2019). This failure became a global 'point of change', which resulted in joint forces between The International Council on Mining and Metals (ICMM), the United Nations Environment Programme (UNEP) and the Principles for Responsible Investment (PRI) to co-convene the Global Tailings Review and produce a Global Industry Standard on Tailings Management (GISTM, 2020) for safe management of tailings storage facilities. The industry is now implementing this standard.

Not just failures of TMFs, but also historical mine sites carrying a negative legacy of environmental and social impacts from TMFs not designed and operated to achieve successful closure, waters the seed of mistrust. The impacts from historical mine sites relate to inappropriate disposal practices, contaminated seepage and associated impacts to surface water and groundwater, and the erosion of tailings and containing structures. A study of remediated mine sites in Sweden (NV \& SGU, 2017:2) states that only 9 of 32 studied sites had established quantitative goals in the remediation plan. Also, almost none of these sites had background data pre mining for evaluation of the effect from mining and remediation. To the knowledge of the authors the situation is similar in other countries as well. These historical legacy sites do not, according to the authors, reflect current leading practice in tailings management as outlined in current guidelines, although their operators may well have complied with leading practice at the time. In many cases resources and money are not available today to manage these according to current best practice.

The mistrust towards the industry is affecting the industry in other ways as well, for example in the permitting processes. These have never been 'easy', and should not be, but the tendency (according to the experience of the authors) are that they are becoming more and more difficult and prolonged without really improving the outcome. The Swedish Association of Mines, Mineral and Metal Producers (Svemin) (February 2020) held a panel discussion on the theme Prolonged permitting processes and provocatively passive politics at their yearly meeting in 2019 and stated that the investment climate is low within the Swedish Mining industry, especially as a result of the current permitting processes. Some junior mining companies are classifying Sweden as a high-risk country to operate in due to the uncertain permitting processes. 
In Sweden a permit for a dam (a structure holding tailings and/or water) be valid for a maximum of 10-year construction period. As the application process normally take years (approx. $5+/-2$ ), mines are more or less continuously in a phase of preparing a permit application or in an application process. The level of technical detail has also increased, and is relatively high, resulting in the mining companies focusing on technical aspects more than the communicative and social aspects. It is in most guidelines emphasised that the life cycle process of a mine, and especially closure, needs to be in dialogue with stakeholders, communities and authorities. How to manage this dialogue is, however, not easy but rather complex. To the experience of the authors, this dialogue is generally more of a one-way communication where the mining company inform what is going to happen and what their plans are. Meaningful dialogue is a process that takes time, and which requires trust, collaboration and a mutual understanding of what is reasonable. Time is, unfortunately, often limited as the mining company in many cases need to get the permit in a certain time to keep the operations going. The authors experience is that all parties involved are not really trusting each other and the will to cooperate is not there. This is not necessary because no one wants to, but because the experience is lacking. What if the mining company, authorities, community and stakeholders together 'owned' the closure and closure planning and the mining company 'just' being the responsible chairman of the project?

To manage risks at closure and the time after closure (i.e. for 1.000 years or more) is not easy. Rare or extreme events will statistically happen if the design life is long enough. A conservative design approach is therefore necessary. For closure design, the consequence of extreme events must be considered, and possible measures taken to reduces unwanted consequences. The risk of humans (not 'to' humans) may however, pose the greatest and most unpredictable long-term risk, to both stability and environmental closure measures taken. The risks may include improper land use, excavation, removal of materials/ spillways, artisanal mining, sabotage or vandalism, on purpose or due to lack of knowledge. For this reason, a closed mine site will need someone to take responsibility to make sure closure measures stay intact and land use is kept to what is appropriate for the specific site.

The risk humans pose to closure in combination with the difficulty in predicting future extreme events in a long-term preceptive, has changed the perspective of the concept of 'walk-away solutions'. Around the 1990's to 2010's some, including Bjelkevik (2005), advocated walk-away solutions as the optimal goal of closure. The idea was referring to 'mother nature' and how design of TMFs could mimic natural formations stable in a long-term perspective, i.e. formations from the last ice-age. This concept is, however from the experience of the authors, regarded to be a real challenge and maintenance in perpetuity is more of a reality as states or governments are reluctant to take over the responsibility. Only small and low hazard mines will in reality be able to implement walk-away solutions. So, almost all mines need to have some level of effective, permanent aftercare to continue to meet their commitments, especially those with large TMFs.

Mine closure has aimed, and in many cases still aims, for returning the land to what it was before mining, i.e. blend in the land into the surrounding nature and return "the borrowed land" to nature. This is often achieved by covering the facility using more or less sophisticated cover systems and vegetating the areas. For parts of the mining operations this is possible, i.e. industrial areas. For other parts; like the mine (open pit), TMFs and waste rock dumps this might be more difficult as the 'scar' in the landscape is unrepairable and their shapes may not fit into the surrounding terrain and topography. The TMF (and waste rock dump) usually covered and vegetated, often have a shape with large flat and smooth areas susceptible to erosion. Their shape normally 'designed' by engineers using 'straight lines'. Even if 'walk-away' solutions may not be feasible, mimicking the nature is part of geomorphologic design, and there are very few straight lines in nature. The field of geomorphologic design where the surface shape is designed to manage the expected runoff have developed rapidly. Today there are expertise and programmes available and papers have previously been presented at this very conference.

Existing national and international documents and guidelines (from section 2.2) are all emphasizing the need of planning for closure as well as the need of stabilizing the facilities, the TMF:s and waste rock dumps, regarding physical, chemical, biological, environmental, and social stability. Design teams for closure and technical design are however, in most cases separate teams and often work in parallel (as far as the authors have experienced), which limit the integration of closure into the design. Often closure focuses on how to 
cover the facility and not really the basis for how TMF:s and waste rock dumps are designed and shaped. Traditionally, little focus has generally been directed to possibilities, future possibilities for possible land use after mining. Is it possible to use the affected areas, to create something new after mining? Is there a prospect for mining to be a contribution to the society, in more ways than the commodities (metals and minerals) we all use (but tend to forget where they come from)?

From the above, the authors cannot leave alone the question: Do we miss the opportunities?

Which leads to a number of follow-up questions, such as (but not limited to):

- What is an opportunity?

- Are there opportunities with mining?

- Can mining be used to create something?

- Can mining be used to improve access to land?

- Who is to decide?

The authors believe that the first step is to consider if there are any opportunities? Generalized, we believe that we, the engineers and environmentalists in the mining industry, are not on our own capable of seeing or finding the opportunities. We believe a collaboration between a much broader set of disciplines would help. Disciplines like landscape architects, artist, historians, socialists, anthropologists etc. in meaningful collaboration with stakeholders, communities and regulators would be required in order to create a new mindset and open up for new strategies which could take mining into a new paradigm. An opportunity must be defined and accepted by the users of the land after mining, which in itself is difficult to define, i.e. who are the users after life of mine (LOM)? The LOM plan many today be 20 years, but in 10 years' time it may be another 30 years.

How do mining companies, ultimately responsible for the mining operations and its closure, create an environment for an open and transparent dialogue and collaboration? The general mistrust towards the industry in combination with the historical one-way dialogue relationship is not easy to reverse and change. The limited experience in participating in the process and make a change towards engaging all parties is slow and takes time and effort from all parties. Mine closure is a shared responsibility; we all need the metals; we all want the operation to be safe and we all want to benefit from the area after closure. Participation must happen in a responsible way by all parties. There must be sensible limits to what the mining company is expected to do and pay for. We need to make sure the money and resources available are used efficiently in order to achieve the best outcome. For this trust is a must.

Mining is the industry, globally, managing the largest volumes/tonnes of materials. These materials (tailings and waste rock) are generally seen as a problem by all parties involved, i.e. a waste product difficult and costly to manage. Can this material possibly be to any use? Normally when we construct things (roads, airports, harbours, official buildings, houses etc.) we move material, often quite a lot of material. These 'normal' building project usually has an architect, responsible for the design, and a design engineer, responsible for the structural design including stability etc., but in mining there is normally no architect involved. Can we, similarly to other building projects, involve other disciplines and change mining into a building project? Is it possible to use mining to create a new landscape, a new land use beneficial to the society without posing harm to the environment? Yes, it may cost more and the material is in many cases hazardous and still need to be managed and covered etc. in a proper way. Hazardous materials need, however, to be covered independent of the shape of the facility (i.e. a waste rock dump or a TMF).

In many cases communities have grown up around mines and in these cases, there is normally a need for something to replace the mine after closure. If a new value can be created, it will not just replace the role (or part of the role) the mine has had, but also give an incitement for 'someone' to maintain and look after the site. Whatever closure measures taken maintenance, in perpetuity, is required. The only way (according to the authors) to ensure that is to turn the mine site into land with a new value for humans and the community. 
What is an opportunity? What can be created? As often in the mining industry, and elsewhere, there are no such thing as 'one solution fits all'. There are, however, good examples out there already. Below are just two examples (Figure 1):

- Northumberlandia (Lady of the north) next to Cramlington North England, https://www.northumberlandia.com/ (March 2020)

- Eden Project in Cornwall South West England, https://www.edenproject.com/ (March 2020)
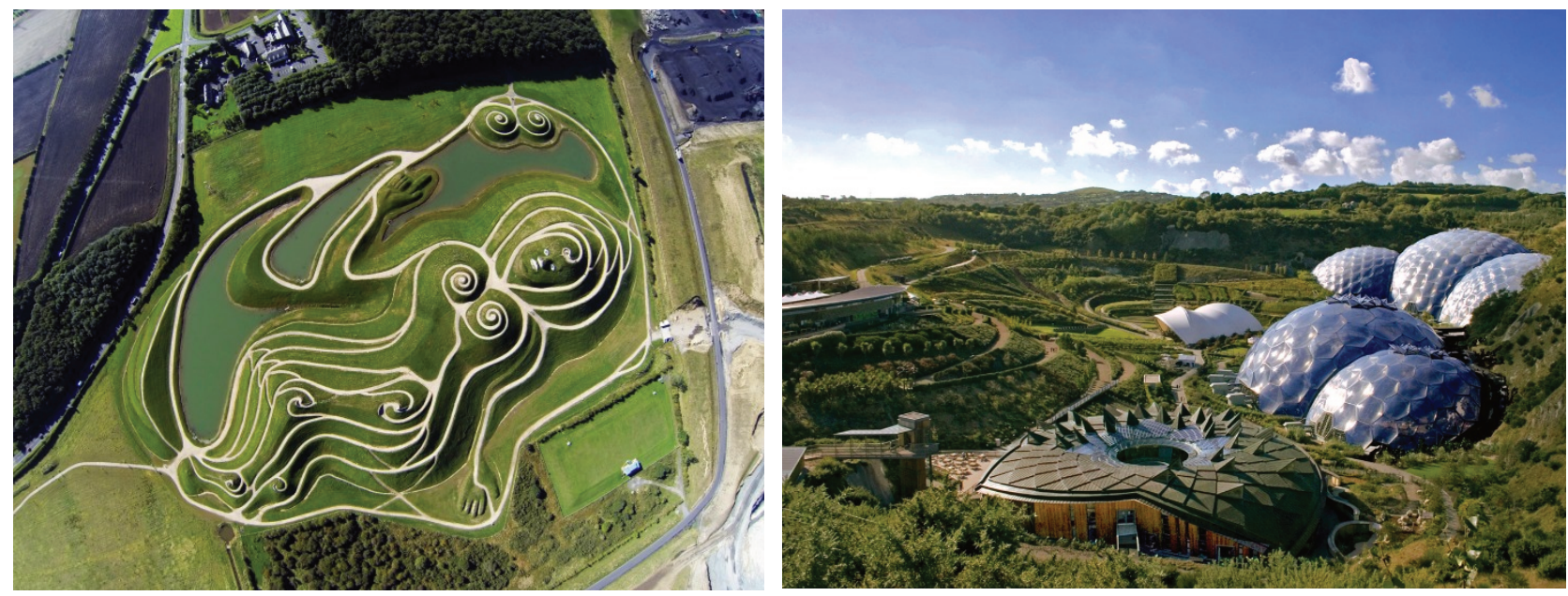

Figure 1. Photos of Lady of the North (left), Eden Project (right).

These two examples show that it is possible to turn mining activities, or part of mining activities, into something positive, something valuable to the community.

A well planned mining operation, including closure, where the final land use has been decided upon in agreement between all parties involved may not just result in stable and safe structures but also lower costs as there will not be too many surprises along the way.

Conventional economic analysis, pushing investments into the future, lead to minimizing initial capital expenditure and deferring rehabilitation costs. Net present value analysis discounts the current cost of future expenditures on closure, rehabilitation, and post-closure management and reduce the motivation to invest more substantially at the development phase to avoid or reduce expenditures at the closure phase. There are however reasons for applying leading practice at the earliest stage of development and for designing and operating mining operations to achieve optimal closure outcomes. This to avoid significant earthworks expenditures to re-establish stable landforms and drainage systems at closure.

A proper life cycle mining operation may cost a bit more, and maybe we, society, need to accept that commodity prices must rise? Maybe we all must understand that we need to pay 'the full price' for the metals and minerals we use? As consumers we might be the root cause to the problem, if we are not accepting to pay the price metals and minerals actually cost?

Progressive rehabilitation, where possible during operations, enables rehabilitation costs to be reduced by eliminating double-handling, allowing the work to be completed while there is an operational cash flow and management and resources are available. Progressive rehabilitation of a TMF enables evaluation of full "pilot" tests with the potential to reduce post-closure monitoring and maintenance as well as regulatory financial costs.

\section{Conclusion}

Mining is something our society needs, and the impact of mining is inevitably. In order to use phones, computers, cars etc. we need metals, and even more so with the green transformation we have to accept 
that mining have an impact. The impact must, i.e. the change of the natural landscape and the environmental must be acceptable. Safety is crucial, but also final land use.

Tailings management facilities (TMF:s) pose in many cases the number one legacies of a mining operation, which after closure are required to remain stable and safe with no detrimental effects to the society and environment in perpetuity or at least for 1.000 years or more. Poorly designed or managed closure of TMF:S result in ongoing impacts for the society and on environment, or at worst in a failure with unacceptable consequences, and costs. TMF:s need to be designed for closure which is influencing the location of TMF:S as well as design and tailings disposal methods in order to minimise the costs of closure, the future risks to the environment and the legacy for future generations. The design teams of TMF:s, for both operation and closure, therefore need to work together and the plans must be integrated with the LOM plan so that the most cost-effective and acceptable risk solution for operation and closure is achieved.

To achieve this all relevant parties; stakeholders, communities and regulators need to be engaged and involved throughout the whole design process, i.e. from the early planning process to the point of transferring the liability. In many cases this is emphasised in the various documents and guidelines as 'meaningful engagement'. In reality, this is not really happening (GTR, 2020). It may sound simple in theory but is definitely more difficult in reality. The authors believe the difficulty originates from; the mistrust between parties, the history of one-way informative communication and that it is not really clear what responsibility lies with the other parties.

Regarding the mistrust, mining companies 'simply' have to improve and show that they and their operations can be trusted, which require clear intentions, good communication and hard work. Trust is easily lost, but hard to regain.

Regarding the history of one-way informative communication, a change is going to be slow as other parties are not used to really participate. The mining companies will have to change the way of communicating to engaging, by doing this in ways different from the tradition of most cases today, i.e. something like a 2-4 $\mathrm{h}$ meeting. Mining companies do want to do things 'right' and change has already started but has not really spread within the industry. There are a few examples in Sweden where the mining companies are changing and try to fully engage the whole community, however, these projects are yet in an early phase.

Regarding the not so clear responsibility lying with other parties, the authors believe that mining companies must take the lead of the closure process. However, other parties, stakeholders, communities and authorities must also acknowledge their responsibility, which compared to today need to increase. They need to really become part of the closure team, and not just 'victims' demanding as much as possible.

We (the mining industry) need to 'think outside the box' and stop do things the same way we have so far. For this change to take place new professions needs to be brought into mining and mine closure and everyone affected need to be part of the process. Business as usual is no longer accepted and to step out of a approx. 100 -year-old path and into a new our mindset needs to change, which is both difficult and takes time. The authors believe, however, that the industry have reach 'the point of no return' where a change is not an option, but indispensable. Other building projects struggle with the problem of finding and moving the right material for the use in construction, whereas the mining industry struggle with having the material but no building project. We, the mining industry, 'just' need to find out what to build. Yes, the materials from mining operations may be hazardous and require correct treatment, but the material needs to be treated no matter the shape of the facility.

The authors believe it is possible to change the mining industry from being an industry producing metals to an industry creating new landscapes and new possibilities for the society and the local communities, i.e. to create a value after mining, while producing metals. By this many things can be achieved like improved; reputation, society/community engagement, long term commitment, more safe long-term solutions as well as incentive to look after and maintain the closed mine site. The 'era of walk-away solutions' have passed, and long-term monitoring and maintenance is for most sites inevitably. A new value, after closure, will give the incitement for someone to look after the site. The guidance in various documents and guidelines are 
already there, the industry and other parties involved just have to implement them fully, and for that all parties (stakeholders, communities and regulators) will need to truly collaborate.

The authors believe that if a change takes place, many of the problems faced by the industry today may dissolve, as bad reputation and difficult and prolonged permitting and that this will improve stability, environment and social safety as well. There is no one solution fits all, but the authors are convinced many opportunities are today missed. A change may increase the costs, and if that is the case we (the society) have to be prepared to pay the 'real' price for the metals we use, i.e. we must allow commodity prices to increase if we want to have a sustainable mining industry.

\section{References}

ANCOLD 2012, 'Guidelines on Tailings Dams. Planning, design, construction, operation and closure', Australian National Committee on Large Dams Incorporated, May 2012, ISBN: 978-0-9808192-4-3.

Australian Government 2016, 'Tailings Management. Leading Practice Sustainable Development Program for the Mining Industry', Australian Government, September 2016, industry.gov.au, dfat.gov.au, www.ag.gov.au.

Bjelkevik 2005, 'Stability of tailings dams: focus on water cover closure', Licentiate Thesis at Luleå University of Technology, Department of Civil and Environmental Engineering, Division of Geotechnology. 2005:85, ISSN: 1402-1757, ISRN: LTU-LIC -05/85 -- SE

CDA 2013, 'Dam Safety Guidelines 2007 (2013 Edition)', CDA/ACB Canadian Dam Association/Association Canadienne des Barrages, www.cda.ca, ISBN 978-0-9936319-0-0

EU 2018, 'Best Available Techniques (BAT) Reference Document for the Management of Waste from Extractive Industries' in accordance with Directive 2006/21/EC, European Union, JRC109657, EUR 28963 EN, PDF ISBN 978-92-79-77178-1, ISSN 18319424, Print ISSN 1018-5593, ISBN 978-92-79-77179-8, Luxembourg: Publications Office of the European Union, 2018, https://ec.europa.eu/jrc

GISTM 2020, 'Global Industry Standard on Tailings Management', Global Tailings Review, International Council on Mining \& Metals (ICMM), UN Environment Programme (UNEP) and Principles for Responsible Investment (PRI), August 2020, https://globaltailingsreview.org/global-industry-standard/

GruvRIDAS 2021, 'GruvRIDAS - Gruvbranschens riktlinjer för dammsäkerhet, Guideline for Tailings Dam Safety' The guideline is under ongoing revision with the main document to be published in 2021 and associated technical documents updated from 2021 and onwards (previous edition 2012). Svensk Energi AB / Svemin 2021, https://www.energiforetagen.se/kc/etjansterna/ridas/gruvridas/

GTR 2020, 'Towards Zero Harm' A compendium of papers prepared for the global tailings review, Chapter VIII Closure and Reclamation, Global Tailings Review, August 2020. https://globaltailingsreview.org/

ICMM 2019, Integrated Mine Closure: Good practice guide (2nd edition, 2019), International Council on Mining \& Metals, 2019, https://www.icmm.com/en-gb/environment/mine-closure/integrated-mining-closure

ICOLD 2013, ICOLD Bulletin 153. 'Sustainable Design and Post-Closure Performance of Tailings Dams', International Commission on Large Dams, 61 avenue Kléber - Paris - 75116. www.icold-cigb.net

NV \& SGU 2017:1, 'Förslag till strategi för hantering av gruvavfall. Redovisning av ett regeringsuppdrag', Proposed strategy for an environmentally sustainable management of mining waste, Naturvårdsverket (NV), Environmental Protection Agency, och Sveriges geologiska undersökning (SGU), Geological Survey of Sweden, September 2017. Ärendenr: NV-03195-16, SGU: 311$888 / 2016$

NV \& SGU 2017:2, 'Delrapportering av regeringsuppdrag Strategi för hantering av gruvavfall', Utvärdering av efterbehandlad gruvverksamhet, Naturvårdsverket (NV), Environmental Protection Agency, och Sveriges geologiska undersökning (SGU), Geological Survey of Sweden, March 2017, RR 2017:04, Ärendenr: NV-03195-16, SGU: 311-888/2016

RIDAS 2019, 'RIDAS - Guideline for Dam Safety'. Swedish Energy, 2020. https://www.energiforetagen.se/forlag/e-tjansterwebbshop/ridas-energiforetagens-riktlinjer-for-dammsakerhet/

RIR 2015, 'Gruvavfall - Ekonomiska risker för staten. En granskningsrapport från riksrevisionen RIR 2015:20', Mine waste - Financial risks for the government. A review report by the Swedish National Audit Office, Stockholm 2015, ISBN 978-91-7086-389-9

Robertson et.al. 2019, 'Report of the Expert Panel on the Technical Causes of the Failure of Feijão Dam I'. Expert panel: Peter K. Robertson, Ph.D. (Chair), Lucas de Melo, Ph.D., David J. Williams, Ph.D. and G. Ward Wilson, Ph.D. December 2019, http://www.b1technicalinvestigation.com/

Sveriges Riksdag 1998, 'Miljöbalk' (1998:808), The Environmental Code (1998:808), Sveriges Riksdag, Miljö- och energidepartementet, Swedish Parliament, Department of Environment and Energy June 1998, https://www.riksdagen.se/sv/dokument-lagar/dokument/svensk-forfattningssamling/miljobalk-1998808_sfs-1998-808

Sveriges Riksdag 2013, 'Förordning om utvinningsavfall' (SFS 2013:319), The Swedish Regulation on extraction of waste (SFS 2013:319), Sveriges Riksdag, Miljö- och energidepartementet, Swedish Parliament, Department of Environment and Energy, May 2013, https://www.riksdagen.se/sv/dokument-lagar/dokument/svensk-forfattnings samling /forordning-2013319-omutvinningsavfall_sfs-2013-319

Wise Uranium 2021, Web page https://www.wise-uranium.org/mdaf.html, June 2021 